\title{
Caracterização sísmica e gravimétrica da litosfera sob a linha de refração sísmica profunda de Porangatu, Província Tocantins, Brasil Central
}

\author{
Dhébora Batista Rosa Ventura ${ }^{1}$, José Eduardo Pereira Soares ${ }^{2}$ Reinhardt Adolfo Fuck ${ }^{2}$ \& \\ Lucas da Costa Coutrim Caridade ${ }^{2}$
}

\begin{abstract}
Resumo Resultado recente de função do receptor na região de Novo Planalto reacendeu a discussão sobre a estrutura da litosfera no limite da Província Tocantins com a Placa Amazônica. Com o intuito de melhor caracterizar a transição entre estes domínios geológicos e discutir a natureza da crosta inferior sob a linha de Porangatu, este trabalho inferiu a espessura da crosta sob o tiro 2 da linha de refração, utilizando a técnica função do receptor; refinou o modelo da crosta na região; determinou a distribuição de densidades por meio de modelagem gravimétrica; e integrou os resultados. Análise conjunta de dados sísmicos e gravimétricos mostrou a existência de domínio crustal diferenciado a oeste da Serra Azul, evidenciado pelo espessamento abrupto da crosta e pelo aumento de densidade da crosta inferior. Valores de Vp e densidade mostram ainda que a crosta inferior sob a linha de Porangatu apresenta composição máfica. De forma geral, os resultados geofísicos mostram que o limite entre a Província Tocantins e a Placa Amazônica, ao longo da linha de refração sísmica profunda de Porangatu, está localizado na Serra Azul, e que este limite é caracterizado por identação de crostas e duplicação da crosta inferior. A diferença entre o manto litosférico Neoproterozóico e os mantos litosféricos mais antigos relacionados às placas Amazônica a NW e São Franciscana a SE é bem definida.
\end{abstract}

Palavras-chave: Modelagem, litosfera, crosta, Moho, Província Tocantins.

\begin{abstract}
Seismic and gravimetric characteristics of the lithosphere beneath the Porangatu deep seismic refraction line, Tocantins Province, Central Brazil. Recent results from receiver function in Novo Planalto region intensified the debate about the lithospheric structure through the limit of Tocantins Province and Amazon plate, in central Brazil. Aiming to better characterize this transition and to discuss the geological nature of the lower crust beneath Porangatu line, this work inferred the thickness of the crust beneath shot 2 of Porangatu line, using receiver function, refined the model of the crust, determined the density distribution by gravimetric modeling and integrated the results. Integrated analysis of seismic and gravimetric data highlighted the existence of a distinct crustal domain west of Serra Azul, evidenced by the abrupt thickening of the crust and the high density of these terranes. Vp and density values also showed that the lower crust beneath Porangatu line is mafic. Geophysical results show that the boundary between Tocantins Province and Amazonian Plate is marked by Serra Azul and that this limit is characterized by crustal interfigering and superposition of lower crusts. Differences between Neoproterozoic and older lithospheric mantle related to Amazonian and São Francisco plate are well defined.
\end{abstract}

Keywords: Modeling, lithosphere, crust, Moho, Tocantins Province.

INTRODUÇÃo No final da década de 90, no escopo do projeto de pesquisa "Estudos Geofísicos e Modelo Tectônico dos Setores Central e Sudeste da Província Tocantins, Brasil Central", financiado pela FAPESP (Berrocal et al. 1998), foram realizados na Província Tocantins estudos sísmicos de refração profunda e função do receptor e estudos complementares de gravimetria, com o objetivo de aprimorar o conhecimento da estrutura da litosfera da Província (Assumpção et al. 2004, Berrocal et al. 2004, Soares et al. 2006, Koosah et al. 2007). No âmbito desse projeto, três linhas de refração sísmica profunda, denominadas Santa Juliana, Porangatu e Cavalcante, foram efetivadas.

A linha de refração de Santa Juliana, realizada na parte sul da Província Tocantins, cruza o limite da província com a Bacia do Paraná (Perosi \& Berrocal 2001, Araújo et al. 2007). As linhas de Porangatu e Cavalcante, que formam perfil contínuo de aproximadamente $550 \mathrm{~km}$ na direção WNW-ESE, cruzam os terrenos da Faixa Brasília Norte e o limite desta com o Cráton São Francisco (Soares et al. 2003, 2006, Berrocal et al. 2004, Melo et al. 2006).

A linha de Porangatu utilizou aproximadamente 120 sensores sismográficos distribuídos ao longo de cerca de $320 \mathrm{~km}$ de extensão e tiros a cada $50 \mathrm{~km}$ ao longo da linha (Fig. 1). Seu início se dá a oeste de São Miguel do Araguaia (GO), enquanto os últimos sensores posicionam-se a leste de Minaçu (GO). Ocupa

1 - Programa de Pós-graduação, LabLitos, Instituto de Geociência, UnB, Brasília (DF), Brasil. E-mail: dbrventura@gmail.com

2 - LabLitos, Instituto de Geociências, Universidade de Brasília (UnB), Brasília (DF), Brasil. E-mails: soares@unb.br; reinhardt@unb.br; lucas.coutrim@yahoo.com.br 


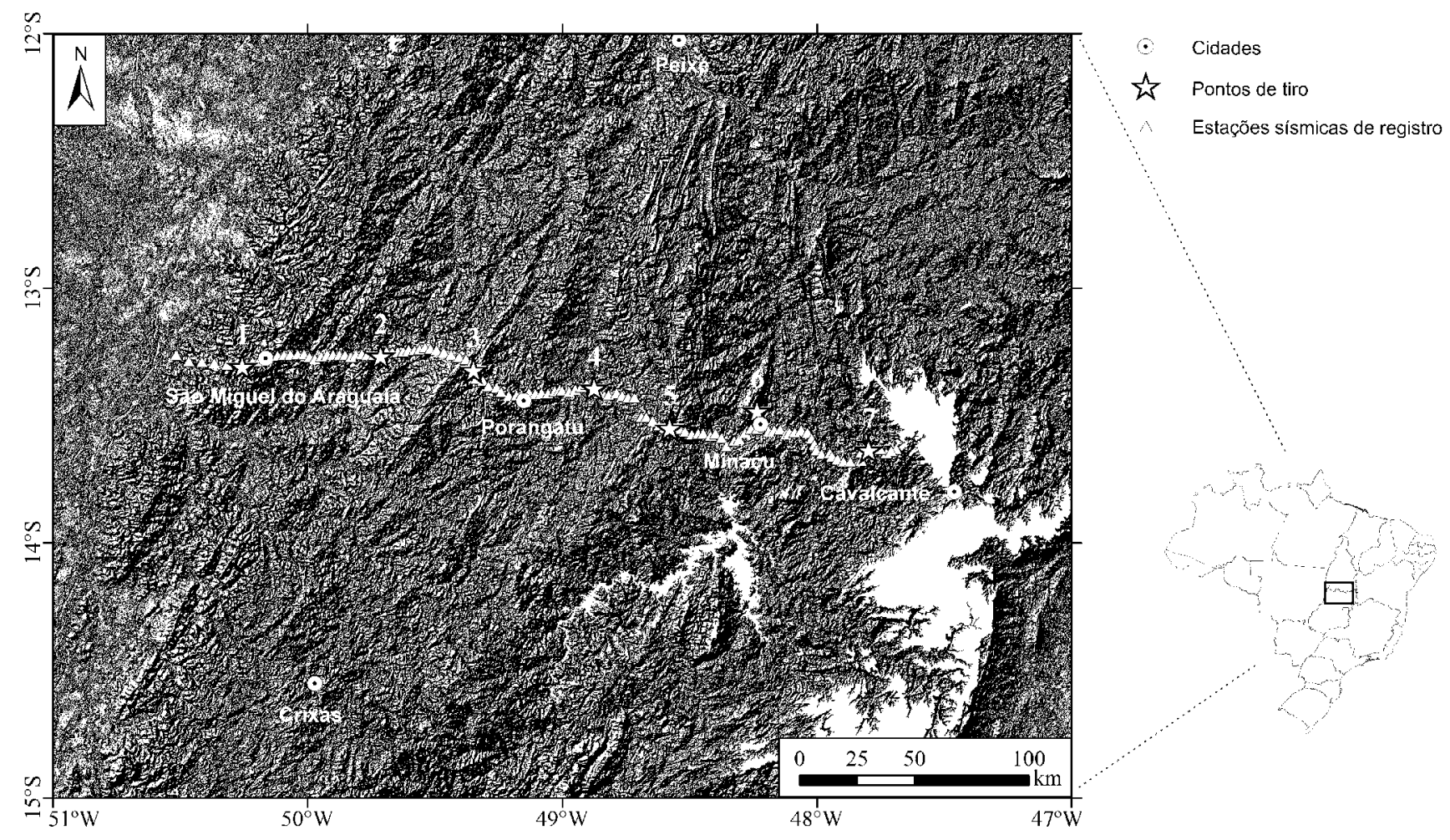

Figura 1 - Mapa topográfico da área de estudo $\left(12-15^{\circ} \mathrm{S} / 47-51^{\circ} \mathrm{W}\right)$ com a localização da linha de refração sísmica profunda de Porangatu. As estrelas mostram o posicionamento das fontes de energia (tiros) e os triângulos, as estações sísmicas de registro. O relevo foi processado a partir de imagem do Shuttle Radar Topography Mission - SRTM (Jarvis et al. 2006).

a porção oeste da Faixa Brasília, região dos terrenos do Arco Magmático de Goiás e do Maciço de Goiás, também marcada pelo alto gravimétrico Bouguer do Brasil central.

$\mathrm{O}$ alto gravimétrico do Brasil central é uma anomalia regional, com aproximadamente $200 \mathrm{~km}$ de largura e $700 \mathrm{~km}$ de extensão na direção NE, caracterizada por valores de anomalia Bouguer entre $+10 \mathrm{mGal}$ e $-10 \mathrm{mGal}$, que contrastam com valores entre $-60 \mathrm{mGal}$ e $-70 \mathrm{mGal}$ a NW e entre $-100 \mathrm{mGal}$ e $-140 \mathrm{mGal}$ a SE (Fig. 2). É interpretada como domínio de manto litosférico neoproterozóico limitado por manto mais antigo e menos denso relacionado às placas Amazônica e São Franciscana (Soares et al. 2006). O limite dos terrenos da Faixa Brasília com a Placa do São Francisco é relativamente bem caracterizado (Assumpção et al. 2004, Soares et al. 2005, 2006, Koosah et al. 2007, Rocha et al. 2010), enquanto o limite com a Placa Amazônica é menos conhecido (Ussami \& Molina 1998).

Os registros das ondas $\mathrm{P}$ do levantamento de refração sísmica de Porangatu foram primeiramente processados e modelados, visando a determinação da estrutura da crosta e do manto litosférico sob o alto gravimétrico Bouguer do Brasil central (Soares et al. 2003, 2006). Posteriormente, refinou-se a parte rasa do modelo com a aplicação de correção estática nos dados e modelagem das fases $\mathrm{S}$ da crosta superior (Melo et al. 2006). Uma das características marcantes da crosta profunda é a existência de degrau na descontinuidade de Mohorovicic, o qual provoca espessamento abrupto da crosta para oeste da SerraAzul (tiro 3). Embora a variação lateral provocada pelo degrau tenha sido detectada, a base do degrau não foi resolvida pela refração. Com o intuito de melhor caracterizar a transição entre a Província Tocantins e a Placa Amazônica sob a linha sísmica e discutir a natureza da crosta inferior sob a linha de Porangatu, este trabalho: i) obteve a espessura da crosta sob o tiro 2 da linha de refração, utilizando a técnica função do receptor; ii) refinou o modelo da crosta, incorporando as contribuições de Melo et al. (2006) para a parte rasa, e modelou a quinta camada crustal; iii) determinou a distribuição de densidades por meio de modelagem 2D do perfil de anomalia Bouguer; e iv) integrou os resultados.

GEOLOGIA REGIONAL Localizada no Brasil central, a Província Tocantins representa extenso orógeno neoproterozóico relacionado à Orogenia Brasiliana/Pan-Africana (Pimentel et al. 2000). Durante este episódio orogenético ocorreu a aglutinação de massas continentais constituintes de Gondwana ocidental, em conseqüência de sucessivas e múltiplas colisões (Cordani et al. 2000, Fuck et al. 2005). Neste contexto, a Província Tocantins resultou da convergência e subseqüente colisão entre os crátons 


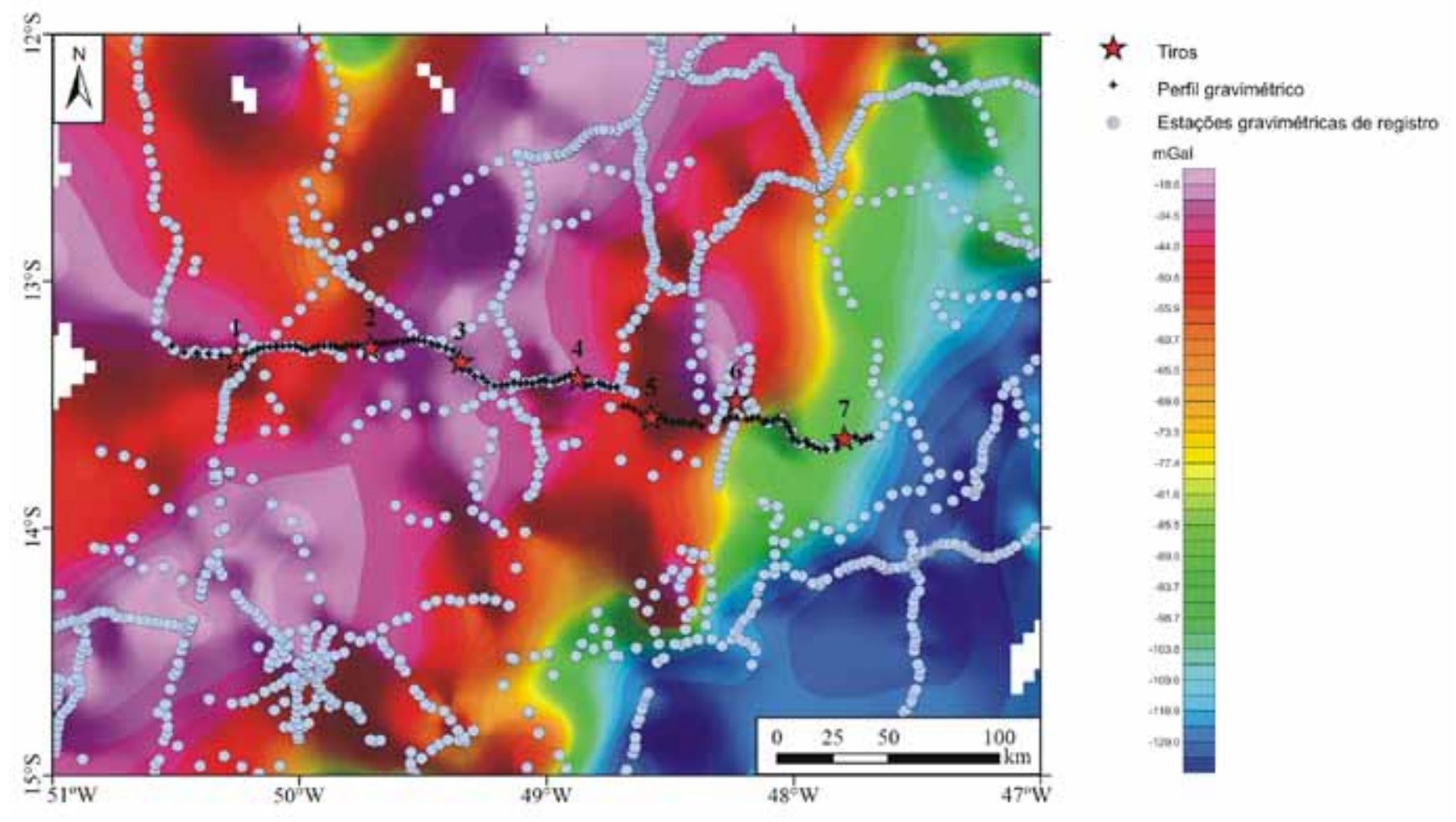

Figura 2 - Mapa de anomalia Bouguer da região da linha de refração sísmica profunda de Porangatu, com a localização das estações gravimétricas de registro e o posicionamento dos pontos de amostragem do perfil gravimétrico.

Amazônico e São Francisco-Congo e um terceiro continente, este último atualmente encoberto pela Bacia do Paraná (Pimentel et al. 2000, 2004).

A linha de refração sísmica profunda de Porangatu atravessa a porção centro-leste da Província Tocantins (Fig. 3). A oeste, inicia-se sobre a Faixa Araguaia e passa, em direção a leste, pela porção norte da Faixa Brasília, onde estações sismográficas foram posicionadas sobre as unidades Arco Magmático de Goiás, Maciço de Goiás e embasamento da zona externa. O Lineamento Transbrasiliano, a Zona de Cisalhamento Rio dos Bois e o Sistema de Falhas Rio Maranhão constituem significativas feições estruturais atravessadas pela linha.

A Faixa Araguaia, localizada na porção noroeste da Província Tocantins, apresenta orientação geral N-S, comprimento de cerca de $1.200 \mathrm{~km}$ e largura superior a $100 \mathrm{~km}$ (Alvarenga et al. 2000). Na área em estudo, a faixa está representada por rochas metassedimentares, as quais recobrem a oeste ortognaisses arqueanos do Cráton Amazônico e capeiam a nordeste terrenos paleoproterozóicos. Na Faixa Araguaia foi detonado o tiro 1 da linha sísmica.

Localizada a leste da Faixa Araguaia, a Faixa Brasília estende-se por cerca de $1.100 \mathrm{~km}$ do oeste de Minas Gerais até o sul de Tocantins, atravessando Goiás (Pimentel et al. 2000). Segundo Pimentel e colaboradores (2000), a Faixa Brasília é provavelmente a faixa orogênica neoproterozóica brasileira mais completa e melhor preservada.

A segmentação da Faixa Brasília adotada neste trabalho é aquela apresentada por Fuck e colaboradores (2005), segundo a qual três compartimentos geológicos distintos constituem a região da linha de refração sísmica profunda de Porangatu. O Arco Magmático de Goiás é o compartimento mais a oeste. Os tiros 2, 3 e 4 da linha de Porangatu foram detonados no domínio do Arco Magmático, sendo que o tiro 4 localizou-se próximo a sua borda leste.

A leste, o Maciço de Goiás é composto por rochas arqueanas e paleoproterozóicas e configura complexo fragmento crustal que aparenta ter sido afetado de forma diferenciada pelos eventos termotectônicos do Orógeno Brasiliano (Fuck 1994). Na região da linha de Porangatu, o Maciço de Goiás é representado pelo Grupo Serra da Mesa, que recobre embasamento paleoproterozóico (Fuck et al. 2005), pela seqüência vulcanossedimentar Palmeirópolis e pelo complexo máfico-ultramáfico acamadado Cana Brava. A detonação do tiro 5 da linha sísmica se deu no Granito Serra Dourada.

Em direção a leste situa-se o terceiro compartimento, a zona externa da Faixa Brasília, a qual compreende unidades do Bloco Almas-Dianópolis. O Sistema de Falhas Rio Maranhão, que separa o Bloco 


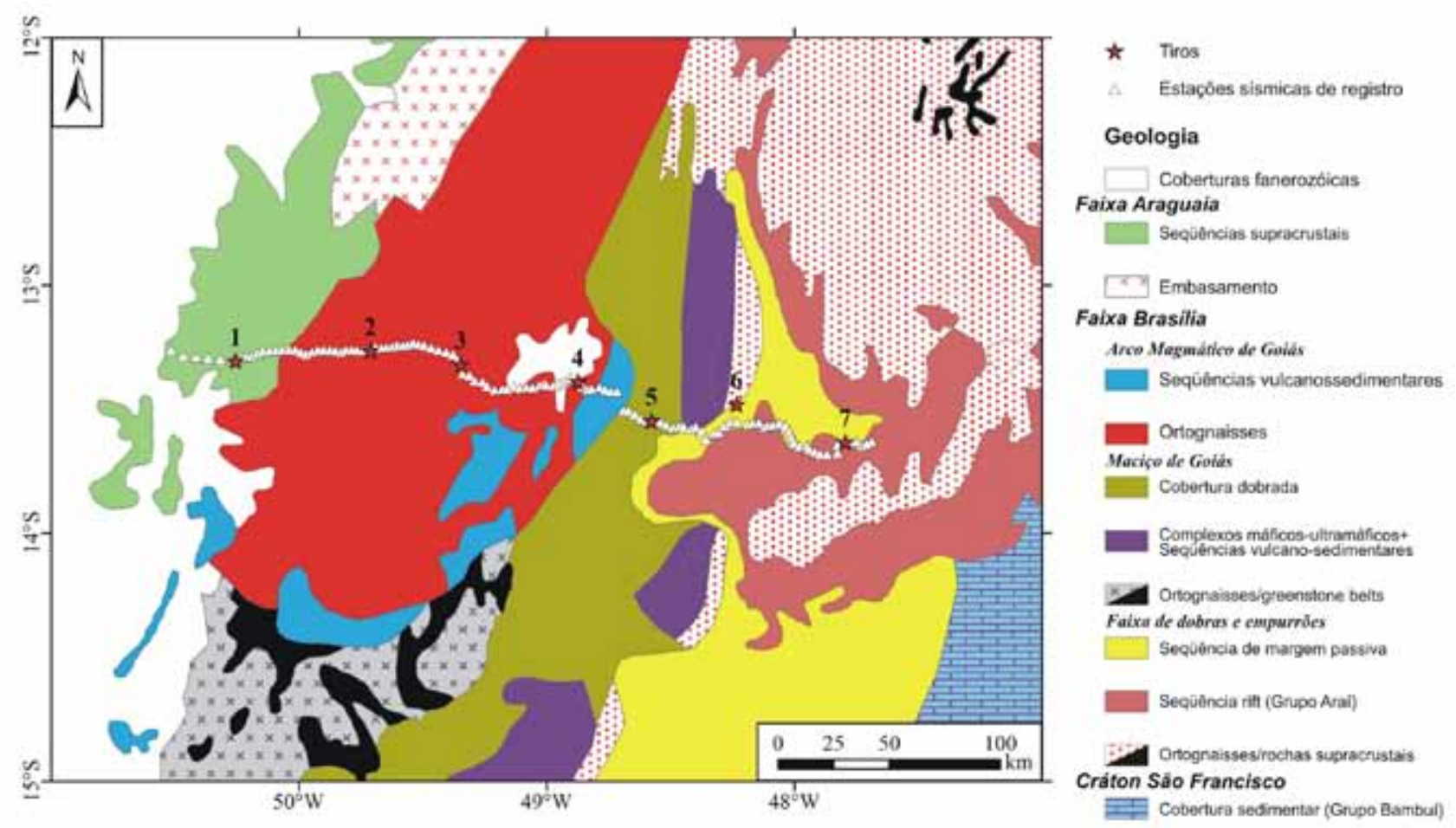

Figura 3 - Mapa geológico da porção norte da Província Tocantins (modificado de Fuck et al. 1994) com a localização da linha de refração sísmica profunda de Porangatu.

Almas-Dianópolis do Maciço de Goiás, é marcado em dados geofísicos por degrau na Moho e importante gradiente gravimétrico (Fuck et al. 2005, Soares et al. 2006). Na região atravessada pela linha sísmica, a zona externa é constituída por exposição de embasamento, por rochas metassedimentares e metavulcânicas do Grupo Araí e por seqüência de margem passiva do Grupo Paranoá.

\section{MÉTODOS}

Métodos sísmicos Em julho de 2008, o Laboratório de Estudos da Litosfera do IG/UnB (LabLitos/IG/ UnB) instalou rede sismográfica de cinco estações de banda larga no Brasil central, no âmbito do projeto de pesquisa "Rede Sismográfica para Estudos Tectônicos no Brasil Central" (FAPDF), com o objetivo de dar continuidade aos estudos da estrutura da litosfera da Província Tocantins. Uma das estações da rede (RET9) foi instalada no mesmo local do tiro 2 da linha de refração sísmica de Porangatu, visando resolver a espessura da crosta na área por meio da aplicação da técnica função do receptor.

Função do receptor permite determinar a estrutura da Terra abaixo da estação sismográfica a partir de registros de telessismos. Mais comumente é aplicada ao estudo da estrutura crustal com a determinação da razão $\mathrm{V}_{\mathrm{p}} / \mathrm{V}_{\mathrm{S}}$ média e da espessura $(\mathrm{H})$ da crosta sob a estação. Quando frentes de ondas telessísmicas incidem próximo à vertical em interfaces abaixo da estação, parte da energia da onda $\mathrm{P}$ é transformada em $\mathrm{S}$ e, em conseqüência, o registro vertical desses eventos contém predominantemente a energia da onda $\mathrm{P}$ e o radial, a energia da onda $\mathrm{S}$ transversal. Deconvolvendo a componente vertical de registro da componente radial, é possível isolar a estrutura da Terra abaixo da estação na forma de uma série temporal, com o primeiro pulso da série contendo a energia da onda $\mathrm{P}$ e os demais pulsos, energia da onda $\mathrm{P}$ convertida em $\mathrm{S}$ (Ps) e em S múltiplas (PpPms, PpSms+PsPms) (Langston 1979). Conhecida a diferença de tempo entre as fases $\mathrm{P}$, Ps e PpPms relativas à Moho e a velocidade média da onda $\mathrm{P}$ na crosta, é possível obter a razão $\mathrm{V}_{\mathrm{P}} / \mathrm{V}_{\mathrm{S}} \mathrm{e}$ a profundidade da Moho sob a estação, utilizando as equações (1) e (2) (Zandt \& Ammon 1995, Zandt et al. 1995, Chevrot \& van der Hilst 2000):

$$
\begin{gathered}
\frac{V_{P}}{V_{S}}=\left\{\left(1-p^{2} V_{P}^{2}\right)\left[2\left(\frac{t_{P S}-t_{P}}{t_{P p P m s}-t_{P S}}\right)+1\right]^{2}+p^{2} V_{P}^{2}\right\}^{1 / 2} \\
\mathrm{e} \\
H=\frac{V_{P}\left(t_{P S}-t_{P}\right)}{\left(\sqrt{\frac{V_{P}^{2}}{V_{S}^{2}}-p^{2} V_{P}^{2}}-\sqrt{1-p^{2} V_{P}^{2}}\right)},
\end{gathered}
$$

onde $t$ representa o tempo de chegada das fases, $V_{P}$ a velocidade média da onda $\mathrm{P}$ na crosta, $\mathrm{V}_{\mathrm{P}} / \mathrm{V}_{\mathrm{S}}$ a razão de velocidades das ondas $\mathrm{Pe} \mathrm{S}, \mathrm{H}$ a profundidade da Moho e $\mathrm{p}$ o parâmetro de raio. $\mathrm{V}_{\mathrm{P}}$ é inferida ou obtida por 
métodos adicionais. A fase Ps da Moho é sempre bem identificada, enquanto a fase múltipla PpPms envolve maiores incertezas.

Levantamentos de refração sísmica profunda utilizam o tempo de propagação de ondas diretas, refletidas de alto ângulo e refratadas para determinar a distribuição de velocidades e a profundidade das descontinuidades mais expressivas da litosfera. Após identificação e classificação dos alinhamentos de fases, os tempos de trânsito são lidos e modelados. Este trabalho utilizou na modelagem o pacote de traçado de raio SEIS88 (Cervený et al. 1997).

Método gravimétrico Os dados gravimétricos utilizados são provenientes de levantamentos do IBGE, IAG/USP, SIS/UnB e LabLitos/UnB, executados em diferentes épocas e com diferentes graus de precisão. As medidas gravimétricas foram realizadas ao longo das estradas regionais e, em particular, da estrada usada como base para o levantamento da linha de refração sísmica de Porangatu. Assim, a coleta de parte dos dados gravimétricos se deu em pontos aproximadamente coincidentes àqueles das estações sísmicas.

Os dados foram pré-processados pelas instituições que os coletaram. Para este trabalho, utilizaram-se os valores de anomalia Bouguer para gerar o mapa de anomalia Bouguer e definir o perfil gravimétrico a ser modelado. O mapa gerado baseouse em 1.290 medidas, irregularmente distribuídas, com célula de $0,05^{\circ}$ e interpolador curvatura mínima (Fig. 2). O perfil gravimétrico foi extraído do mapa, considerando os valores de anomalia Bouguer para as coordenadas geográficas das estações sísmicas de registro.

A modelagem gravimétrica 2D foi realizada de forma direta, considerando o modelo crustal obtido pela sísmica, por meio do programa GM-SYS da Geosoft ${ }^{\mathrm{TM}}$, que utiliza o método proposto por Talwani et al. (1959). A partir da distribuição de $\mathrm{V}_{\mathrm{p}}$, obteve-se a estimativa inicial da distribuição de densidades, utilizando a relação $\mathrm{V}_{\mathrm{P}}$ versus densidade proposta por Christensen \& Mooney (1995). Após, os valores de densidade do modelo foram sendo alterados por tentativa e erro até se obter ajuste considerado satisfatório.

No perfil gravimétrico de campo, os valores de anomalia Bouguer variam entre cerca de $-17 \mathrm{mGal}$ e -105 mGal, com tendência regional de decréscimo dos valores em direção a leste. Anomalias de período curto foram associadas a fontes localizadas entre a primeira e a terceira camada do modelo, enquanto as de grande período refletem variações da crosta inferior e, principalmente, variações de densidade do manto litosférico.

\section{RESULTADOS}

Modelagem sísmica Neste trabalho foram selecionados trinta e seis telessismos com parâmetro de raio entre 5-11 s/grau e magnitude acima de $5,5 \mathrm{mb}$. Obtida no domínio da freqüência, a função do receptor utilizou o pacote de programas de Ammon (1977), com nível d'água igual a 0,001 e filtro passa baixa de Gauss $\left(\left[\exp \left(-w^{2} / 4 a^{2}\right)\right]\right)$ com parâmetro a igual a 2 . Os traços com parâmetros de raio próximos (diferença de p menor que $2,5 \mathrm{~s} / \mathrm{grau}$ ) foram empilhados, independente do azimute, e plotados em função do quadrado do parâmetro de raio $\left(\mathrm{p}^{2}\right)$ para formar sismogramas compostos (Fig. 4). Nestes sismogramas as fases Ps e PpPms tendem a se alinhar segundo retas com coeficiente angular positivo e negativo, respectivamente (França \& Assumpção 2004), o que auxilia a identificação das fases.

As fases Ps foram calculadas com tempo de chegada de $5,5 \mathrm{~s}$ para parâmetro de raio igual a zero $(p=0)$, o que, em princípio, sugere crosta bastante espessa. Com base no modelo sísmico existente, que propõe $\mathrm{V}_{\mathrm{P}}$ de $6,6 \mathrm{~km} / \mathrm{s}$ e $\mathrm{V}_{\mathrm{p}} / \mathrm{V}_{\mathrm{S}}$ de 1,72 para os terrenos imediatamente a oeste da estação, a espessura da crosta foi calculada em $50 \mathrm{~km}$ sob o tiro 2 da linha de Porangatu (Tab. 1). A partir dos resultados de função do receptor, o alinhamento de fases $\mathrm{P}$ de porções profundas do sismograma do tiro 1 (Fig. 5), anteriormente interpretado como possível reflexão em descontinuidades do manto litosférico, foi reanalisado e pôde ser modelado como reflexão da base do degrau. Por modelagem direta 2D foi obtido bom ajuste com a Moho a $50 \mathrm{~km}$ de profundidade e $\mathrm{V}_{\mathrm{p}}$ de $7,29 \mathrm{~km} / \mathrm{s}$ para a quinta camada (Fig. 5).

$A V_{p}$ média da crosta na região do degrau obtida do modelo final é de $7,0 \mathrm{~km} / \mathrm{s}$. Refazendo os cálculos de espessura da crosta com os dados de função do receptor para $\mathrm{V}_{\mathrm{P}}$ de $7,0 \mathrm{~km} / \mathrm{s}$, e utilizando o programa $\mathrm{H}-\mathrm{K}$ stacking (Zhu \& Kanamori 2000), a espessura da crosta aumenta para $52,4 \mathrm{~km}$ com Vp/Vs de 1,72 sob o tiro 2 (Fig. 4, Tab. 1).

Análise dos dados sísmicos de função do receptor e refração profunda possibilitaram refinar a porção oeste do modelo sísmico e definir em aproximadamente $50 \mathrm{~km}$ a espessura da crosta a oeste da Serra Azul, tiro 3 da linha de refração sísmica profunda. Nesta região a crosta sofre abrupto espessamento em profundidade, com a Moho passando bruscamente de $36 \mathrm{~km}\left(\mathrm{~V}_{\mathrm{p}} / \mathrm{V}_{\mathrm{S}}\right.$ de 1,71$)$ a leste da Serra Azul para $50 \mathrm{~km}$ $\left(\mathrm{V}_{\mathrm{P}} / \mathrm{V}_{\mathrm{S}}\right.$ de 1,78$)$ a oeste, criando degrau de $14 \mathrm{~km}$ na base da crosta inferior.

Modelagem gravimétrica A partir do modelo sísmico e do perfil gravimétrico de anomalia Bouguer foi possível apresentar proposta de distribuição de densidades para a crosta e o manto superior sob a linha sísmica. Na figura 6 são indicados os dados de campo (círculos) e os calculados durante a modelagem (linha contínua), bem como o erro entre ambos (linha tracejada). O maior erro de ajuste ocorreu na porção leste do modelo, próximo ao tiro 6 , relacionado a anomalias rasas (alta freqüência). Essa região do perfil é a que possui menor distribuição de medidas gravimétricas, predominando valores obtidos por interpolação de medidas próximas (Fig. 2), fato que, entre outros fatores, ressalta a influência de anomalias laterais. Imediatamente a sul do perfil sísmico/gravimétrico encontra-se o batólito Serra da Mesa, com cerca de 35 

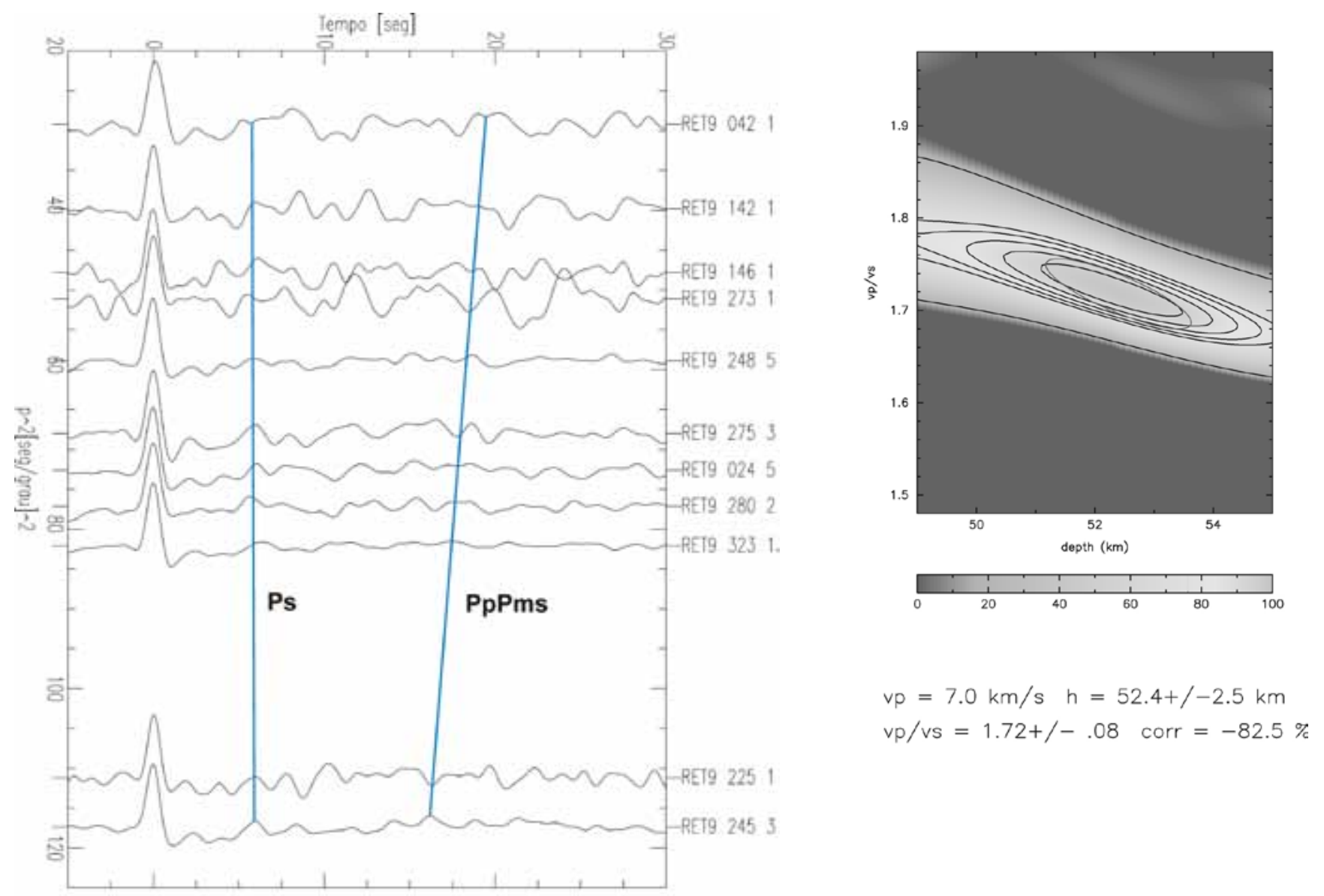

Figura 4 - Traços de função do receptor da estação RET9 empilhados para azimutes e parâmetros de raio (p) similares. O nome ao lado de cada traço significa, respectivamente, estação, azimute médio e número de traços empilhados. Os traços estão plotados segundo o quadrado do parâmetro de raio e o tempo. As fases Ps e PpPms estão interpretadas. $O$ traço abaixo do sismograma composto representa o traço zero offset $(p=0)$, obtido após correção NMO.

Tabela 1 - Resultado de função do receptor da estação RET9, localizada sobre o tiro 2 da linha de refração sísmica profunda de Porangatu.

\begin{tabular}{|c|c|c|c|c|c|c|c|c|}
\hline \multirow{2}{*}{ Estação } & \multicolumn{2}{|c|}{ Localização } & \multirow{2}{*}{$\begin{array}{c}\text { Ps (s) } \\
p=0\end{array}$} & \multirow{2}{*}{$\begin{array}{c}\text { PpPms (s) } \\
\mathbf{p}=0\end{array}$} & \multirow{2}{*}{$\mathbf{V}_{\mathrm{P}} / \mathbf{V}_{\mathrm{s}}$} & \multirow{2}{*}{$\begin{array}{c}\text { H mínimo (km) } \\
\mathrm{Vp}= \\
6.7 \mathrm{~km} / \mathrm{s} \\
\end{array}$} & \multirow{2}{*}{$\begin{array}{c}\text { H máximo (km) } \\
\mathrm{Vp}= \\
7.0 \mathrm{~km} / \mathrm{s}\end{array}$} & \multirow{2}{*}{ Ambiente Geológico } \\
\hline & Latitude $\left({ }^{\circ}\right)$ & Longitude $\left({ }^{\circ}\right)$ & & & & & & \\
\hline RET9 & $-13,29$ & $-49,72$ & 5,50 & 20,67 & 1,72 & 50,1 & 52,4 & $\begin{array}{c}\text { Arco Magmático de Goiás } \\
\text { gradiente gravimétrico Bouguer }\end{array}$ \\
\hline
\end{tabular}

$\mathrm{km}$ de eixo maior, cuja influência lateral nas medidas gravimétricas não pode ser desprezada.

As densidades estimadas para a primeira camada da crosta foram de $2,63 \mathrm{~g} / \mathrm{cm}^{3}$ para a Faixa Araguaia, 2,56-2,60 g/ $\mathrm{cm}^{3}$ para o Arco Magmático de Goiás, $2,64 \mathrm{~g} / \mathrm{cm}^{3}$ para o Maciço de Goiás e $2,57 \mathrm{~g} / \mathrm{cm}^{3}$ para a zona externa da Faixa Brasília. Embora o foco da modelagem gravimétrica não tenha sido a parte rasa do modelo, ao menos quatro anomalias locais expressivas são observadas ao longo do perfil gravimétrico, das quais três correspondem a corpos aflorantes.

A anomalia situada a oeste do tiro 4 corresponde a corpo de baixa densidade não aflorante, modelado com densidade de $2,46 \mathrm{~g} / \mathrm{cm}^{3}$ e profundidade de aproximadamente $2,5 \mathrm{~km}$. Esta anomalia situa-se em região de suítes de granitos, granodioritos e tonalitos relacionados ao Arco Magmático de Goiás (Chiarini 2006), sugerindo que a anomalia represente uma dessas intrusões. 

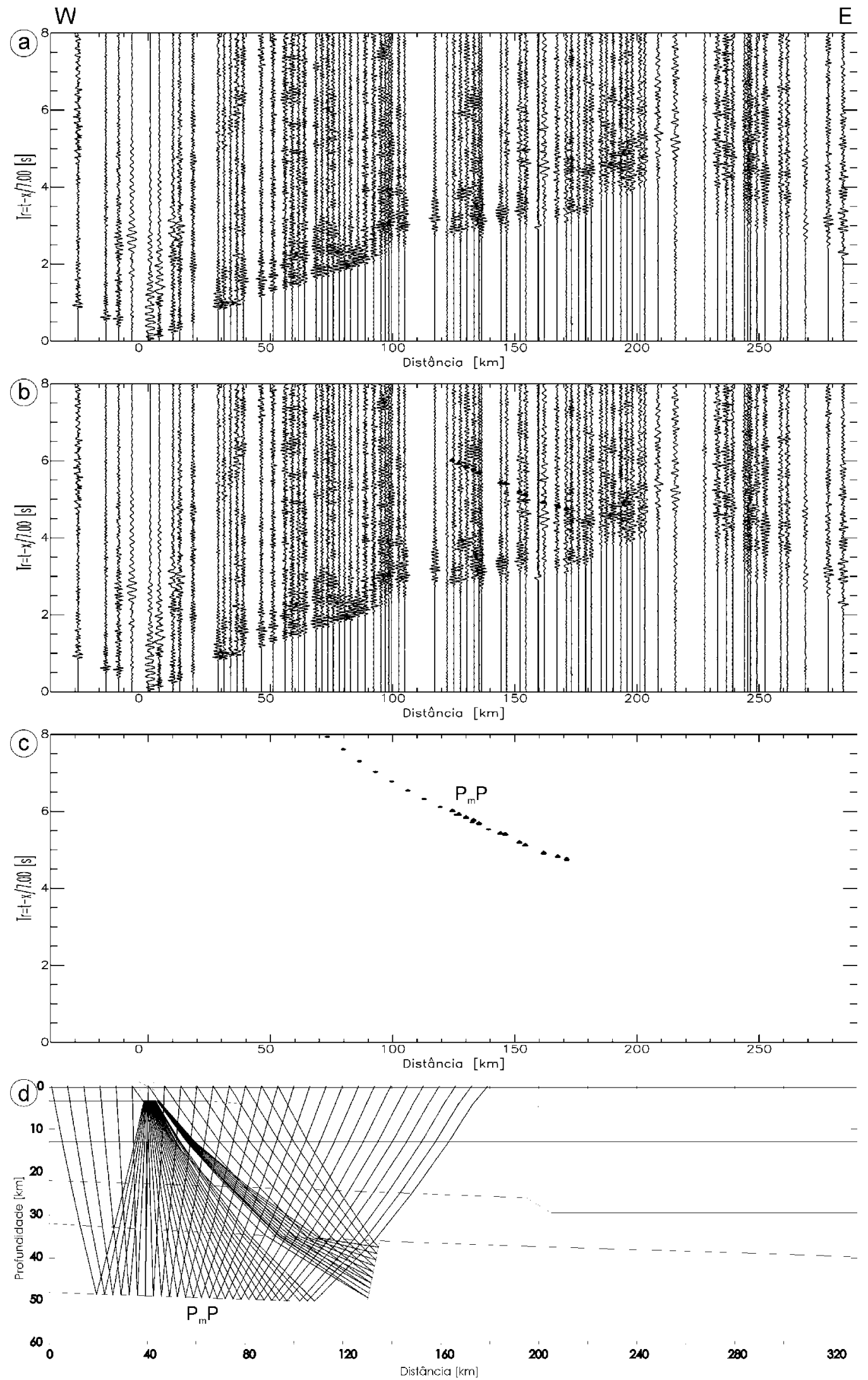

Figura 5 - Modelagem 2D do alinhamento de fases P interpretados como reflexão na base da crosta a leste da Serra Azul para o tiro 1 da linha de refração sísmica profunda de Porangatu. O sismograma foi filtrado na banda-passante de $1 \mathrm{~Hz}$ a $15 \mathrm{~Hz}$ e reduzido com velocidade de $7,0 \mathrm{~km} / \mathrm{s}$. Em (a), (b) e (c) utiliza-se o frame do sismograma do tiro 1, com indicação de fases lidas (b) e modeladas (c). O modelo crustal com traçado de raio é mostrado em (d). A curva é resultado sintético obtido para o modelo de Porangatu com o programa SEIS88. $\mathrm{P}_{\mathrm{m}} \mathrm{P}$ é a reflexão da Moho e os triângulos, as fases de referência lidas. 


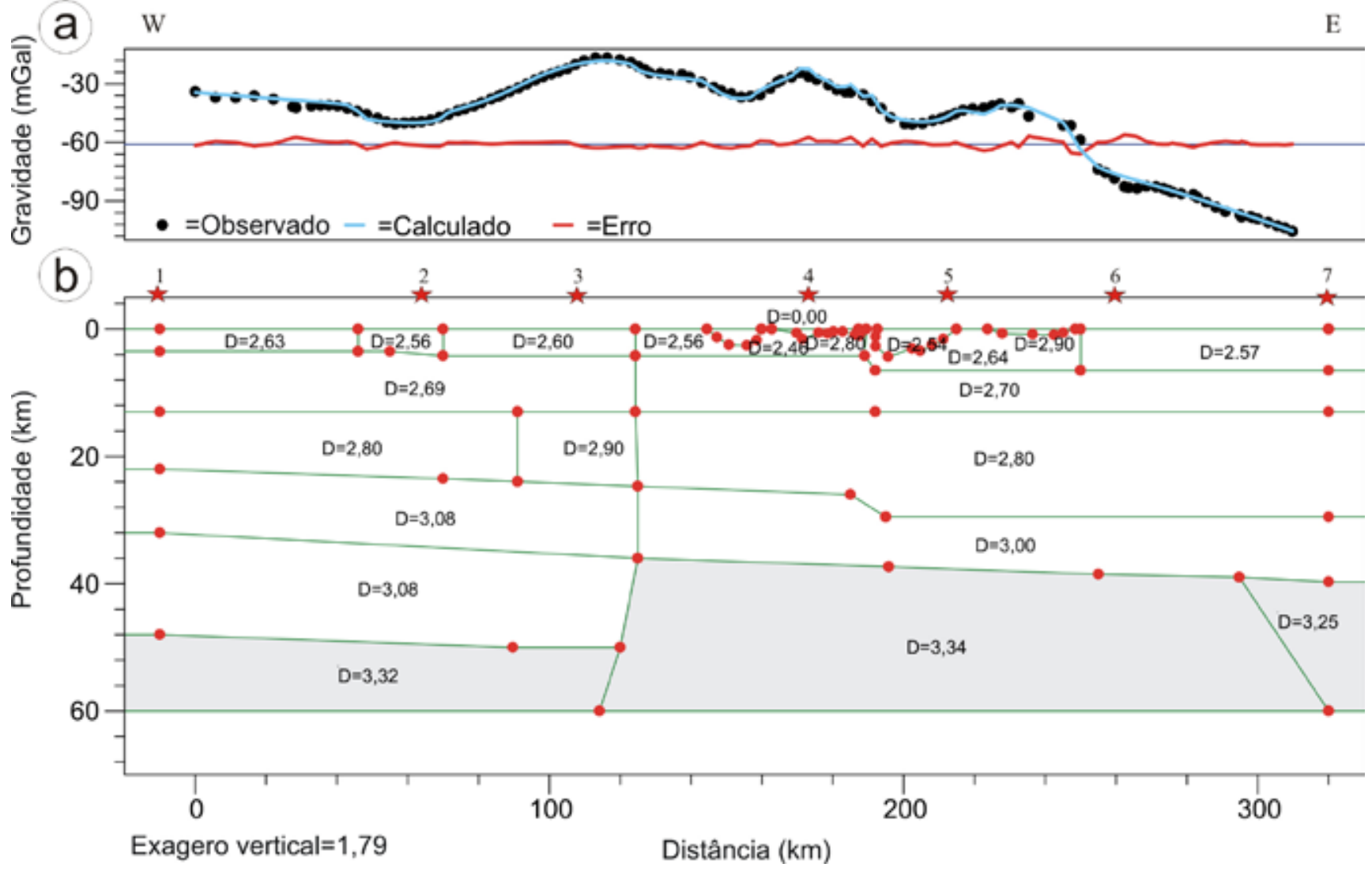

Figura 6 - Modelagem gravimétrica de anomalia Bouguer obtida para a região da linha de refração sísmica profunda de Porangatu. Dados de densidade fornecidos em $\mathrm{g} / \mathrm{cm}^{3}$. No modelo, estrelas indicadam a localização dos tiros da linha sísmica.

Em direção a leste, no tiro 4, aflora anortosito. Para este corpo, a densidade modelada foi de $2,80 \mathrm{~g} / \mathrm{cm}^{3}$, maior que a média de $2,73 \mathrm{~g} / \mathrm{cm}^{3}$ obtida em laboratório para amostras de campo. Este resultado, associado à composição máfica obtida por Melo et al. (2006), utilizando dados sísmicos $\left(\mathrm{V}_{\mathrm{P}}\right.$ versus $\left.\mathrm{V}_{\mathrm{P}} / \mathrm{V}_{\mathrm{S}}\right)$, sugere que o anortosito esteja associado em profundidade a rochas máficas. Neste trabalho o corpo foi modelado com densidade de $2,80 \mathrm{~g} / \mathrm{cm}^{3}$ e $1,2 \mathrm{~km}$ de profundidade.

O Granito Serra Dourada, no tiro 5, foi modelado com densidade de $2,54 \mathrm{~g} / \mathrm{cm}^{3}$ e profundidade de aproximadamente $4 \mathrm{~km}$. A densidade é similar àquela obtida para o corpo não aflorante, localizado cerca de $30 \mathrm{~km}$ a oeste.

A anomalia rasa positiva mais a leste no perfil gravimétrico consiste no complexo máficoultramáfico acamadado de Cana Brava e na seqüência vulcanossedimentar de Palmeirópolis, sobre a qual se localiza o tiro 6. A densidade modelada é de $2,90 \mathrm{~g} /$ $\mathrm{cm}^{3}$, para corpo com cerca de $0,9 \mathrm{~km}$ de profundidade. Amostras do complexo máfico-ultramáfico de Cana Brava apresentam densidade média de $3,02 \mathrm{~g} / \mathrm{cm}^{3}$ e a seqüência vulcanossedimentar de Palmeirópolis de $2,94 \mathrm{~g} / \mathrm{cm}^{3}$ (Carminatti 2006). Considerando que o perfil gravimétrico utilizou pontos de amostragem localizados a sul do complexo e da seqüência, o valor modelado de $2,90 \mathrm{~g} / \mathrm{cm}^{3}$ mostra-se compatível com a média de densidades das rochas da área.

A segunda camada é bastante mais homogênea em termos de distribuição de densidades. $\mathrm{O}$ modelo final apresenta densidade de $2,70 \mathrm{~g} / \mathrm{cm}^{3}$ para toda a crosta a leste da Serra Azul e 2,69 g/ $\mathrm{cm}^{3}$ para região a oeste.

A terceira camada foi modelada com densidade de $2,80 \mathrm{~g} / \mathrm{cm}^{3}$, com pequena região anômala de densidade $2,90 \mathrm{~g} / \mathrm{cm}^{3}$ sob o tiro 3 . Apesar das incertezas envolvidas, esse corpo é necessário para a modelagem de anomalia positiva observada sob a Serra Azul (tiro 3), indicando a presença de possível corpo máfico em subsuperfície. À exceção desta zona de densidade mais elevada, a crosta intermediária apresenta densidade de $2,80 \mathrm{~g} / \mathrm{cm}^{3}$.

A porção inferior da crosta, composta pelas camadas 4 e 5 do modelo, apresenta densidades de 3,08 $\mathrm{g} / \mathrm{cm}^{3}$ a oeste da Serra Azul e 3,00 g/ $\mathrm{cm}^{3}$ a leste, sendo que no bloco oeste a quarta e quinta camadas não se diferenciam (Fig. 6).

Ao longo do perfil gravimétrico o manto apresenta maior densidade $\left(3,34 \mathrm{~g} / \mathrm{cm}^{3}\right)$ na porção central do modelo. No sentido oeste é identificada a influência de possível cunha mantélica de densidade $3,32 \mathrm{~g} / \mathrm{cm}^{3}$, associada à Placa Amazônica e, no sentido 
leste, manto ainda menos denso, da ordem de $3,25 \mathrm{~g} /$ $\mathrm{cm}^{3}$, associado à Placa São Franciscana (Koosah et al. 2007).

A curva de anomalia Bouguer modelada forneceu bom ajuste em relação aos dados medidos em campo. De modo geral, o perfil gravimétrico demonstrou forte influência de anomalias rasas, resolvidas com o posicionamento de intrusões na crosta superior, e de anomalia de grande comprimento de onda, responsável pelo balizamento da tendência gravimétrica regional. $\mathrm{O}$ Lineamento Transbrasiliano, a Zona de Cisalhamento Rio dos Bois e o Sistema de Falhas Rio Maranhão não apresentam expressão em termos de gravimetria.

As variações gravimétricas laterais mais marcantes posicionam-se na crosta inferior, e sugerem diferenças entre os terrenos a oeste e leste do degrau. Os contrastes verticais ressaltam a passagem da crosta média para a crosta inferior e da crosta inferior para o manto, onde ocorrem expressivos contrastes de densidade. De forma geral, o modelo gravimétrico final responde de forma satisfatória à geologia de superfície e apresenta ajuste linear entre $V_{p}$ e densidade, consistente com o proposto na literatura para a crosta.

DISCUSSÃO Identificada como região de escudo e abarcando o extremo leste da Faixa Araguaia e unidades geológicas da Faixa Brasília - Arco Magmático de Goiás, Maciço de Goiás e porção oeste da zona externa - a área atravessada pela linha de refração sísmica profunda de Porangatu é representativa de extensa porção da Província Tocantins (Fig. 3). A localização dos crátons Amazônico e São Francisco, respectivamente nos extremos oeste e leste da linha, aumenta a complexidade geológica da área, visto que toda a região configura orógeno neoproterozóico com diferentes terrenos amalgamados por meio de zonas de subducção atuantes nas bordas desses crátons.

A análise conjunta dos dados geofísicos mostra a existência de domínio crustal diferenciado a oeste da Serra Azul, evidenciado pelo espessamento abrupto da crosta de $36 \mathrm{~km}$ para $50 \mathrm{~km}$ e pelo aumento de densidade da crosta inferior de $3,00 \mathrm{~g} / \mathrm{cm}^{3}$ para 3,08 $\mathrm{g} / \mathrm{cm}^{3}$. O espessamento anormal da crosta sugere a ocorrência de duplicação crustal na região, mostrando o comportamento da crosta na frente de colisão, onde provavelmente houve superposição de crosta inferior dos terrenos da borda leste da Placa Amazônica com crosta inferior dos terrenos da borda oeste da Província Tocantins.

Os valores de $\mathrm{V}_{\mathrm{p}}$ e densidade, principalmente os valores de densidades, sugerem que a crosta inferior sob a linha de Porangatu seja de composição máfica. A porção da crosta inferior situada a leste do degrau, sob o domínio dos terrenos do Arco Magmático de Goiás e Maciço de Goiás, se apresenta bastante homogênea, apesar das diferenças geológicas, sugerindo possível retrabalhamento da crosta inferior no Neoprotrozóico. A quinta camada do modelo, com $V_{P}$ de $7,29 \mathrm{~km} / \mathrm{s}$ e densidade de $3,08 \mathrm{~g} / \mathrm{cm}^{3}$, parece representar porção reliquiar da crosta oceânica da Placa Amazônica subductada sob os terrenos do Arco Magmático de Goiás ou, alternativamente, que a crosta inferior da porção continental dos terrenos da Placa Amazônica seja de composição máfica.

A modelagem gravimétrica mostrou ainda a variação de densidade no manto litosférico, com densidades modeladas compatíveis com densidades obtidas em compilações mundiais de mantos litosféricos arqueano e proterozóico (O'Reilly et al. 2001). Confirmou que o alto gravimétrico Bouguer do Brasil central marca os limites de domínio do manto Neoproterozóico, com possível composição primitiva $\left(3,34 \mathrm{~g} / \mathrm{cm}^{3}\right.$ - mais denso, apesar de mais quente), em contraste com o manto litosférico das placas Amazônica a WNW e São Franciscana a ESE, considerado depletado $\left(3,32 \mathrm{~g} / \mathrm{cm}^{3}\right)$ e ultradepletado $\left(3,25 \mathrm{~g} / \mathrm{cm}^{3}\right)$, respectivamente. Muito provavelmente essas litosferas antigas se comportaram como blocos rígidos no Neoproterozóico, sendo pouco afetadas durante a formação da Província Tocantins, no Brasil central. A região do alto gravimétrico é onde se espera encontrar registros de maior atividade ígnea, com geração de crosta juvenil e possível retrabalhamento de terrenos antigos.

\section{CONCLUSÕES}

1) Combinada com os resultados sísmicos, a modelagem gravimétrica se torna robusta. Apesar do bom ajuste da curva de campo com combinações de densidade um pouco distintas, as variações possíveis não afetam as análises regionais.

2) Os resultados gravimétricos foram determinantes para definir composição máfica para a crosta inferior sob a linha de Porangatu e diferenciar a crosta inferior em segmentos a oeste e leste da Serra Azul.

3) Os $50 \mathrm{~km}$ de espessura da crosta a oeste da Serra Azul caracterizam superposição de crostas inferiores.

4) Após o término do consumo da porção oceânica da placa, ocorre choque entre as porções continentais dos diferentes continentes, gerando interpenetração de crostas na frente de colisão, com conseqüente espessamento, onde possíveis lascas tectônicas de terrenos mais antigos são colocados em meio a terrenos juvenis e vice-versa. Essa região de crosta anormalmente espessa a oeste da Serra Azul é possivelmente uma região de interpenetração de crostas (interfingering) e a Serra Azul pode ser uma lasca de rochas do embasamento do Cráton Amazônico obductada no processo de colisão.

5) O conjunto de dados geofísicos mostra que a frente de colisão entre a Placa Amazônica e a Província Tocantins, ao longo da linha sísmica, tem seu limite na Serra Azul. Em outras palavras, é ali que se localiza a zona de sutura entre as duas paleoplacas.

Agradecimentos Os autores agradecem à FAPESP pelo financiamento ao projeto "Estudos Geofísicos e 
Modelo Tectônico dos Setores Central e Sudeste da Província Tocantins, Brasil Central" e à FAPDF pelo suporte ao projeto "Rede Sismográfica para Estudos Tectônicos no Brasil Central" (Proc. 193.000.209/2007). Ao curso de pós-graduação em Geociências Aplicadas do IG/UnB pelo apoio ao desenvolvimento da dissertação de Mestrado que originou este artigo. Ao Laboratório de Geofísica Aplicada pelo uso do programa GM-SYS da Geosoft ${ }^{\mathrm{TM}}$, e à $\operatorname{Prof}^{\mathrm{a}} \mathrm{Dr}^{\mathrm{a}}$ Roberta Mary Vidotti pelas orientações e discussões durante a modelagem gravimétrica.

\section{Referências}

Alvarenga C.J.S.de, Moura C.A.V., Gorayeb P.S.deS., Abreu F.deA.M.de. 2000. Paraguay and Araguaia Belts. In: Cordani U.G., Milani E.J., Thomaz Filho A., Campos D.A. (eds.) Tectonic Evolution of South America. International Geological Congress, $31^{\text {st }}$, Rio de Janeiro, Abstract, p. 183-194.

Ammon C.J. 1997. An overview of receiver function analysis. Citação de referências e documentos eletrônicos. Disponível em: http://www.essc.psu.edu/ ammom/ HTML/RftnDocs/rftn01.html. Acessado em jun 1998.

Araújo V.C., Soares J. E. P., França G.S.L.A., Berrocal Jesus. 2007. Crustal model of the Paraná Basin-Brasília Belt boundary: a deep refraction approach. In: SBGf, International Congress of the Brazilian Geophysical Society, $10^{\text {th }}$, Rio de Janeiro, Anais, CD-Rom.

Assumpção M., An M., Bianchi M., França G., Rocha M., Barbosa J.R. Berrocal J. 2004. Seismic studies of the Brasília Fold Belt at the western border of the São Francisco Craton, central Brazil, using receiver function, surface wave dispersion, and teleseismic tomography. Tectonophysics, 388:173-185.

Berrocal J., Marangoni Y., Côgo de Sá N., Fuck R.A., Soares J.E.P, Dantas E., Perosi F., Fernandes C. 2004. Deep seismic refraction and gravity crustal model and tectonic deformation in Tocantins Province, Central Brazil. Tectonophysics, 388:187-199.

Carminatti M.G. 2006. Modelagem geofísica dos corpos máfico-ultramáficos de Cana Brava, Niquelândia e Barro Alto, Centro de Goiás. Tese de Doutoramento, Instituto de Astronomia, Geofísica e Ciências Atmosféricas, Universidade de São Paulo, 293 p.

Cervený V., Molotkov J. \& Psencik I. 1977. Ray Methods in Seismology. Charles University, Prague.

Chevrot S \& van der Hilst R.D. 2000. The Poisson ratio of the Australian crust: geological and geophysical implications. Earth and Planetary Science Letters, 183:121-132.

Chiarini M.F.N. 2006. Contribuição da aerogeofísica na caracterização de suturas e de sistemas transcorrentes: o exemplo de Porangatu. Dissertação de Mestrado $n^{\circ}$ 231, Instituto de Geociências, Universidade de Brasília, $108 \mathrm{p}$.

Christensen N.I. \& Mooney W.D. 1995. Seismic velocity structure and composition of the continental crust: a global view. Journal of Geophysical Research, 100(B7):9761-9788.

Cordani U.G., Sato K., Teixeira W., Tassinari C.C.G., Basei M.A.S. 2000. Crustal evolution of the South American Platform. In: Cordani U.G., Milani E.J., Thomaz Filho A., Campos D.A. (eds.) Tectonic Evolution of South
America. In: International Geological Congress, $31^{\text {st }}$, Rio de Janeiro, Abstract, p. 19-40.

França G.S.L.A. \& Assumpção M. 2004. Crustal structure of the Ribeira Fold Belt, SE Brazil, derived from receiver functions. Journal of South American Earth Science, 16:743-758.

Fuck R.A. 1994. A Faixa Brasília e a compartimentação tectônica na Província Tocantins. In: SBG, Simpósio de Geologia do Centro-Oeste, 4, Atas, p. 184-187.

Fuck R.A., Pimentel M.M., Silva L.J.H.D. 1994. Compartimentação tectônica na porção oriental da Província Tocantins. In: SBG, Congresso Brasileiro de Geologia, 38, 1, Atas, p. 215-216.

Fuck R.A., Pimentel M.M., Soares J.E.P., Dantas E.L. 2005. Compartimentação da Faixa Brasília. In: SBG, Simpósio de Geologia do Centro-Oeste, 9, Atas, p. 26-27.

Jarvis A., Reuter H.I., Nelson A., Guevara E. 2006. Holefilled seamless SRTM data V3. International Centre for Tropical Agriculture (CIAT). Citação de referências e documentos eletrônicos. Disponível em http://srtm.csi. cgiar.org. Acessado em 26 abr 2008.

Koosah M., Vidotti R., Soares J.E.P., Fuck R.A. 2007. Gravimetric and seismic data integration in a 2D forward gravimetric modeling for the crust and lid mantle beneath northern Brasilia Belt. In: SBGf, Internat. Cong. of the Brazilian Geophy. Soc., 10 ${ }^{\text {th }}$, Rio de Janeiro, Expanded Abstract Volume, CD-Rom.

Langston C.A. 1979. Structure under Mountain Rainier, Washington, inferred from teleseismic body waves. Journal of Geophysical Research, 84:4749-4762.

Melo S.S., Soares J.E.P., Fuck R.A. 2006. Razão de Poisson da crosta superior da região de Porangatu, Goiás, Província Tocantins: um estudo por refração sísmica. In: SBG, Congresso Brasileiro de Geologia, 43, Aracaju, Resumo Expandido, p. 192.

O’Reilly S.Y., Griffin W.L., Djomani Y.H.P., Morgan P. 2001. Are lithospheres forever? Tracking changes in subcontinental lithospheric mantle through time. GSA Today, 11(4):4-10.

Perosi F.A. \& Berrocal J.A. 2001. Levantamento de Refração Sísmica Profunda no Setor Sudeste da Província Tocantins. In: SBGf, International Congress of the Brazilian Geophysical Society, $7^{\text {th }}$, Salvador, Anais, CDRom.

Pimentel M.M., Fuck R.A., Jost H., Ferreira Filho C.F., Araújo S.M. 2000. The basement of the Brasília fold belt and the Goiás Magmatic Arc. In: Cordani U.G., Milani E.J., Thomaz Filho A., Campos D.A. (eds.) Tectonic Evolution of South America. International Geological Congress, $31^{\text {st }}$, Rio de Janeiro, p. 195-230. 
Pimentel M.M., Jost H., Fuck R.A. 2004. O embasamento da Faixa Brasília e o Arco Magmático de Goiás. In: V. Mantesso-Neto, A. Bartorelli, C.D.R. Carneiro, B.B.de Brito-Neves (eds.) Geologia do Continente Sul-Americano: evolução da obra de Fernando Flávio Marques de Almeida. São Paulo, Editora Beca, p. $355-$ 370.

Rocha M.P., Schimmel M., Assumpção M. 2011. Uppermantle seismic structure beneath SE and Central Brazil from P- and S-wave regional travel-time tomography. Geophysical Journal International, 184:268-286.

Soares J.E.P, Berrocal J., Fuck R.A. 2003. Seismic crustal structure in central Brazil. In: SBGf, International Congress of the Brazilian Geophysical Society, $8^{\text {th }}$, expanded abstract volume, CD-Rom.

Soares J.P., Berrocal J., Fuck R.A., Mooney W., Ventura D.B.R. 2006. Seismic characteristics of central Brazil crust and upper mantle: a deep seismic refraction study. Journal of Geophysical Research, 111:B12302, doi:10.1029/2005JB003769.

Soares J.E.P., Fuck R.A., Berrocal J. 2005. Geophysical signature of the lithosphere at the western border of São Francisco plate. In: SBG, Simpósio sobre o Cráton do
São Francisco, 3, Salvador, Anais, 1:48-51.

Talwani M., Worzel J.L., Landisman M. 1959. Rapid gravity computations for two dimensional bodies with application to the Mondocino submarine fracture zone. Journal of Geophysical Research, 64(1):49-59.

Ussami N. \& Molina E.C. 1999. Flexural modeling of the Araguaia Belt, Central Brazil. Journal of South American Earth Sciences, Inglaterra, 12(1):1-12.

Zandt G. \& Ammon C.J. 1995. Continental crust composition constrained by measurements of crustal Poisson's ratio. Nature, 374:152-154.

Zandt G., Myers S.C., Wallace T.C. 1995. Crust and mantle structure across the Basin and Range-Colorado Plateau boundary at $37^{\circ} \mathrm{N}$ latitude and implications for Cenozoic extensional mechanism. Journal of Geophysical Research, 100:10529-10548.

Zhu L. \& Kanamori H. 2000. Moho depth variation in southern California from teleseismic receiver functions. Journal of Geophysical Research, 105:2969-2980.

Manuscrito ID 16640

Submetido em 22 de janeiro de 2010 Aceito em 24 de fevereiro de 2011 